\title{
A PROPOSED APPROACH TO TRAINING FASHION STUDENTS ON CREATIVITY FACTORS: RIBBONS FASHION TREND AS A MODEL
}

\author{
Rehab Ragab Mahmoud Hassaan \\ Prof. Dr. University of Nizwa, OMAN. Helwan University, Egypt, rehab.ragab@unizwa.edu.om
}

\begin{abstract}
The current study aims to propose an approach to train fashion students on creativity factors (originality, fluency, flexibility, sensitivity, and elaboration), the proposed approach have been examined through the study experiment at University of Nizwa, Fall semester 2021/2022, the experiment could be summarized in teaching and designing a ribbon fashion collection, the researcher divided fashion students into two groups, experimental and control, (10) students for each, , the researcher/professor taught the control group the section of (Ribbons Fashion Trend) in conventional methods, presenting definitions and comprehensive analysing of fashion examples in contrast to the experimental group, the researcher/designer have designed (12) creative ribbons fashion designs on mannequin, presenting adequate analysis how creativity factors enabled the designer/professor to consist an entire collection, then the researcher assigned the two groups (20 students) to sketching ribbons fashion, (5) designs in one sheet for each, the (20) collection sheets had been measured by fashion professors through a Valuing Questionnaire which had been designed by the researcher, the reliability and validity of the questionnaire had been approved, the results proved the hypothesis for the experimental group: Training fashion students on creativity factors throughout an entire designs collection, indicating each factor role (originality, fluency, flexibility, sensitivity, and elaboration) in proposing a creative collection is enhancing creative thinking of the students/designers in proposing their fashion collections.
\end{abstract}

Keywords: Fashion designing, ribbons fashion trend, creativity factors, fashion students, fashion teaching, dyed fashion, fabrics manipulation, (originality, fluency, flexibility, problem sensitivity, and elaboration).

\section{INTRODUCTION}

Education provides opportunities for students to engage in creative activities, it broadens their knowledge base and experiences, subsequently enhancing their chances of creative results (Williams, Ostward, Askland, 2017), the creativity can foster and promoted by providing appropriate environment and favourable learning conditions, the characteristics underpinning creativity can be developed (Cropley, 1997).

"Research on the phenomenon of creativity and discussion with the concept are limited, the most common definition suggests that creativity in design relates to the development of ideas or work that has the quality of being both useful and original" (Askland, 2010) (Amabile, 1996) (Elton, 2006) (Mayer, 1999), it plays a very important role in the process of culture reproduction, invention, technological advancement and innovation, across the design disciplines there is no sharing about creative process applying through learning and teaching experience the definition of creativity balances between form and function, novelty and appropriateness, which are on the priority for each design concern (Paulus, 2003) (Sternberg, 1999) 
(Yamacli, 2006), creativity enables the talented designers to transcend conventional representations to new concepts, ideas and forms which may lead to innovative solutions, design converts from routine solutions to nonroutine solutions and innovative standard. The conceptual thinking regarding creativity in design has changed over time depending on some factors, these factors can be named (4P) as follows: PersonProduct- Process- Press, will be explained in detail throughout (Askland, 2010). There is a close relationship between creativity and design.

Creative thinking can be defined as mental activities aiming to direct the designer desire to for original solutions that were unknown before (Jarwan, 2005) breaking up of old ideas, finding out new relations, widening the limits of knowledge and the onset of wonderful ideas (Taleb, Hamza, Wefky, 2013)

\section{STUDY QUESTION}

What is the effect of analysing the creativity factors as an approach on improving the creative thinking skills of fashion students at University of Nizwa in designing their innovative collections?

\section{HYPOTHESIS}

Regarding to the research question, the researcher hypothesizes:

Training students of the fashion program on creativity factors (originality, fluency, flexibility, problem sensitivity, and elaboration) through designing and analyzing an innovative fashion collection, this enhances students' creative thinking skills when designing their collections.

\section{OBJECTIVES}

1-Enhancing students' creative thinking skills as fashion designers through fashion program courses, direct and indirect courses.

2-Proposing and Producing creative fashion designs by the researcher and by the students.

3- Creating a proposed scheme for designing fashion using dyed ribbons.

4-Proposing creative approaches in designing fashion, which leading intellectual abilities of fashion students.

\section{SIGNIFICANCE}

1- Proposing creative thinking approaches enhances and develops design courses teaching.

2-The proposed approach can be applied in other design courses.

3-The proposed approach benefits the fashion students and designers alike.

\section{BACKGROUND}

Pervious studies were chosen directly related to the subject of the research and benefit from the results afterwards:

(Taleb, Hamza, Wefky, 2013) explored the effect of using brainstorming strategy in teaching science on improve creative thinking, some differences have been found in students' creative thinking skills for experimental group. The results shown that there is statistical significant difference between the experimental group that has been taught by brain storming strategy and the control group that has been taught by traditional method, the strategy made students ready to participate in the sessions as well as joy environment that doesn't contain interferences and critics.

(Demirkan, Afacan, 2011) aimed to explore creativity in design education and identify the creativity assessment indicators in the first-year design studio. A measurement tool of 41 items were utilised for assessment the students' artifacts, results of exploratory and confirmatory factor analysis indicated three main design creativity factors: novelty, elaboration and the third factor consist of repletion, rhythm, and unity.

(Demrikan, 2010) discussed the interaction between person, creative product, creative process, and creative environment in designing architecture, these four elements of creativity were claimed to act together, this result supports the current study result that creativity five factors alike must act together for producing a creative design (the flexibility, originality, fluency, sensitivity, and elaboration). Alike (Hennessey, 1994) tried to find out a set of fundamental criteria in assessing process of manufacturing the creative product.

(Askland, Ostwald, Williams, 2010) considered the main approaches to creativity within the design disciplines and the changing nature of conceptual thinking regarding creativity in design, the study aimed to explore the 
perception of creativity embedded in the design literature, discussed the distinction between routine and nonroutine design process, routine ones are recognized as not being different from previous designs. In contrast, nonroutine designs are those recognized as being different from previous designs. Results of the study match with current study results that creativity is complex phenomenon in which aspects related to person, process, product, and press. Results also indicated that understanding creativity requires an understanding of cognitive characteristics as they relate to creative process (flexibility, imagination, aesthetic taste, decisional skills, intellectuality, and integration).

(Williams, Ostwald, Askland, 2011) tried to explore and investigate the concept behind creativity, tried to answer the question: What creativity means in relation to education and specifically, design education, the purpose of the study is to initiate a discussion about creativity and designing process creatively, also the paper addressed the subject of administrative problem through the question: How can we asses creativity in a way that national standards of quality assurance?

(Horn, \& Salvendy, 2006, 2009) investigated the composition of product creativity by analyzing the elements of product creativity from the consumer perspective, the results represent in proposing six factors: novelty, desire, importance, emotion, resolution, and centrality. (Keritler, Casakin, 2010) investigated the most influential indicators from nine indicators, (fluency, flexibility, innovation, functionality, elaboration, aesthetics in representation, fulfilling design requirements, context, and overall creativity), they found out three indicators that are the most influential ones, as follows: flexibility, fluency, and overall creativity.

\section{METHODOLOGY}

\subsection{Research Design}

The study followed the experimental Approach according to comparing control group and experimental group against each other in an experiment. The only difference between the two groups is that the independent variable is changed in the experimental group. The proposed approach of Creativity Factors Analyses represents the independent variable.

\subsection{Sample of the study}

(20) Fashion Design Program students', divided into two groups, (20) the total, the experimental $(\mathrm{N}=10)$ and the control $(\mathrm{N}=10)$ groups, the students had been selected randomly. (2) fashion designers and professors to assess the students' proposed designs.

\subsection{Procedure}

The study was conducted at University of Nizwa (UoN) Fall semester 2021/2022. One of the groups was randomly assigned to be the control group, and the other as the experimental group. The control group was taught traditionally, using ready fashion designs through internet searching to analyses the trend of Ribbons Fashion -the title-, the contents included: Definitions and displaying+ analysing fashion designs through internet images, the practical class assignment: Creating a collection of Fashion Ribbons Trend.

The experimental group was taught same definitions of Ribbons Fashion Trend but using the proposed designs of the experiment, the (12) designs were implemented by the researcher/ professor, the researcher/professor displayed the designs details and analysed the manipulation technique in forming the dyed ribbons to create new fashion, and how the designer considered the creative thinking factors when design (originality, fluency, flexibility, sensitivity, and elaboration).

\subsection{Instrument}

The instrument used in this study was a valuing questionnaire, the questionnaire was designed by the researcher to assess the students designs of the practical lecture (Ribbons Fashion Trend), each student designed one paper sheet includes a ribbons fashion collection consists of five designs, the total number is (20) sheets by the two groups.

The questionnaire comprised of (20) items, covering (4) axes, experts within the field were asked to mark each item on a 5-point Likert scale

\subsubsection{Reliability and Validity of the Research Instrument}

The valuing questionnaire have been designed by the researcher to measure the creativity factors of students designs, the questionnaire consists of (4) axes that including (20) statements, (5) for the first axis, (6) for the second axis, (5) for the third axis and (4) for the fourth axis. The reliability of the scale was verified 
by presenting it to a group of supervisors, and then the scale was put in its final form. The validity of the scale was confirmed by Cronbach's alpha as 0.95 , which confirms its validity for application. The scale and the students' work were presented to a group of faculty members specializing in fashion, design and arts, and the evaluating was measured by Likert's five-point scale, (1=poor; 2=poor-average; $3=a v e r a g e$; $4=$ average-excellent; $5=$ excellent). so that the highest score for the scale is (100) and the lowest score is (20).

A pilot study was conducted with a small sample. The overall internal consistency was verified to insure the consistency of the assessments $(\alpha=0.95, n=5$ items). Total of 20 items for the final rating scale.

\section{CREATIVITY FACTORS}

8.1 Originality: The ability to produce ideas that are unconventional or unique responses.

8.2 Fluency: Ability to make multiple answers to same given information in a limited time, and quantity of meaningful solutions. A component of creativity that signifies the smooth flow or vibration of substance or emotions that resonates with a unique symbol or norm.

8.3 Flexibility: Adaptability to change instructions, freedom from inertia of thought and spontaneous shift of set. It refers to the ability to produce a large variety of ideas such as thinking of varied uses of object.

8.4 Problem Sensitivity: The ability to find problem and to aware needs for change or for new devices or methods.

8.5 Elaboration: The realization or transformation of an idea, which may become very general or simple or in contrary very fantastic or enriched into details. The number of added ideas demonstrates the subject's ability to develop and elaborates ideas.

\section{9. (RIBBONS FASHION TREND): THE EXPERIMENTAL SECTION}

Roseman and Gero argue that it is impossible to initiate a creative process from nothing, it should be a starting point, according to their perspective there are two approaches for creative design: 1) starting from existing elements and modify them to produce the creative new design or protype, 2) configuring new elements, the current experiment confirms the important role of exploration attitude for innovation new designs.

In the current experiment, the researcher taught same section of (Ribbons Fashion) to the control group and the experimental, using different approaches:

Experiment Preparation: 1) Dyeing white cotton fabric using food colours by the students.

2) Designing a ribbons fashion collection by the researcher/professor, forming coloured dyed ribbons on mannequin within manipulating techniques after reinforcing the dyed ribbons.

Experiment Conducting: 3) Teaching the lecture of (Ribbons Fashion: Trend and Design) to the control and experimental groups.

4) Assigning the students control/experimental groups, (20) female students, (10) for each group to propose a fashion collection consist of (5) designs on one sheet by each student.

Measuring: 5) Measuring the achieving of creativity abilities in the students proposed designs by fashion design professors.

6)Accessing the statistical results of the Valuing Rating scale.

Table (1): Teaching the experimental lesson of (Ribbons Fashion: Trend and Design)

\begin{tabular}{|l|l|l|}
\hline & Control Group & $\begin{array}{l}\text { Experimental } \\
\text { (The proposed Approach) }\end{array}$ \\
\hline Objectives & $\begin{array}{l}\text { Theory section: } \\
\text {-Recognizing definitions of (trend } \\
\text { - fashion trend - fashion ribbons) } \\
\text { - Analysing ribbons fashion which }\end{array}$ & $\begin{array}{l}\text { Recognizing definitions of (trend - } \\
\text { fashion trend - fashion ribbons) } \\
\text {-Analysing ribbons fashion }\end{array}$ \\
\hline
\end{tabular}




\begin{tabular}{|c|c|c|}
\hline & $\begin{array}{l}\text { designed by international } \\
\text { designers. } \\
\text { Practical application: } \\
\text {-Applying Ribbons Fashion } \\
\text { designing in unconventional } \\
\text { ideas. }\end{array}$ & $\begin{array}{l}\text { designed by the professor. } \\
\text { Practical application: } \\
\text {-Raising the capability of creative } \\
\text { designing for the fashion trend } \\
\text { (Ribbons Fashion). }\end{array}$ \\
\hline Content & $\begin{array}{l}\text { Theory: } \\
\text { Definitions of: Trend- Fashion } \\
\text { trend- Ribbons fashion- Ribbons } \\
\text { fashion trend. } \\
\text { Practice: } \\
\text { Designing a collection of } \\
\text { unconventional ribbons fashion } \\
\text { (apply ribbons in unusual locating } \\
\text { on garments) }\end{array}$ & $\begin{array}{l}\text { Theory: } \\
\text { Definitions of: Trend- Fashion } \\
\text { trend- Ribbons fashion- Ribbons } \\
\text { fashion trend- Manipulation } \\
\text { techniques. } \\
\text { Practice: } \\
\text { Designing a collection of } \\
\text { innovative ribbons fashion, } \\
\text { considering the creativity abilities } \\
\text { (originality, fluency, flexibility, } \\
\text { problem sensitivity, and } \\
\text { elaboration) within applying } \\
\text { manipulating techniques on the } \\
\text { ribbons. }\end{array}$ \\
\hline Educational Activities & $\begin{array}{l}\text { Collecting an album of ribbons } \\
\text { fashion designs images. }\end{array}$ & Ribbons manipulating \\
\hline Educational Media & $\begin{array}{l}\text { PPT presentation- drawing } \\
\text { sketches of ribbons fashion. }\end{array}$ & $\begin{array}{l}\text { PPT presentation- Manipulating } \\
\text { dyed ribbons on mannequin in } \\
\text { different forms. }\end{array}$ \\
\hline Assignments & $\begin{array}{l}\text { (5) designs sketches of ribbons } \\
\text { fashion on a } A 3 \text { sheet. }\end{array}$ & $\begin{array}{l}\text { (5) designs sketches of ribbons } \\
\text { fashion on a A3 sheet. }\end{array}$ \\
\hline Assessment & $\begin{array}{l}\text { Within the study instrument (The } \\
\text { Values rating scale). }\end{array}$ & $\begin{array}{l}\text { Within the study instrument (The } \\
\text { Values rating scale). }\end{array}$ \\
\hline
\end{tabular}

\section{CREATIVITY IN DESIGN EDUCATION: THE CURRENT EXPERIMENT}

\subsection{Ribbons Manipulations}

The author used dyed fabrics to form many ribbons in different widths, several reasons were behind this idea of manipulating the dyed ribbons, that the researcher found the previous fashion designers used the ribbons in conventional forms, as laces in the clothes, or they put them in places other than their usual places, but in the same shape, where the ribbons still retain their identity as soft and hanged smoothly and flexible.

Architects like Thomas Heatherwick often applies paper folding techniques in architectural work. And for decades, Japanese fashion designer Issey Miyake has applied the pleating techniques in his collections. $\mathrm{He}$ invented the 'garment pleating technique' back in the 80s and launched the Pleats Please collection in 1994, which is consisted of light, stretchable and wrinkle-proof garments for all shapes and sizes. In recent years, Miyake and his Reality Lab. team also launched IN-EI, an innovative lighting line produced by Italian lighting company Artemide. (Toothpicker, 2019). For create innovative designs belong to the trend of the study Ribbons Fashion- the author reinforced a set of ribbons which are differing in width, manipulated them on mannequin, following paper manipulation techniques, as (cutting, rolling, folding, fringing, weaving, curling, and looping). Figures 1:12 indicates the implemented designs which are designed by the researcher to been analysed through the study experiment to the experimental students group. 

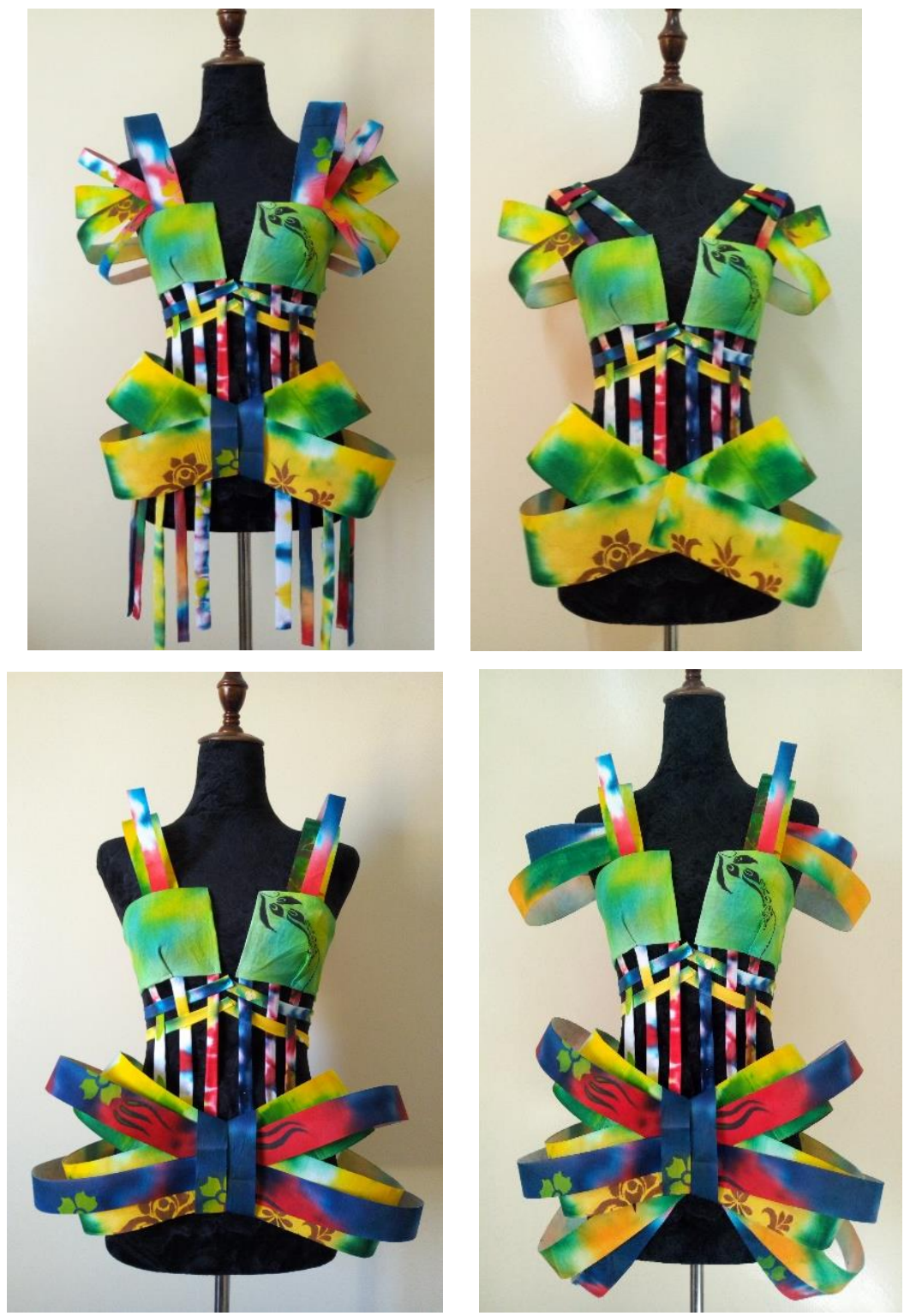

Designs 1. 2. 3. 4: Reinforced dyed ribbons, manipulated and designed on mannequin by the researcher/professor (manipulation techniques: looping-cutting-fringing-weaving and folding)
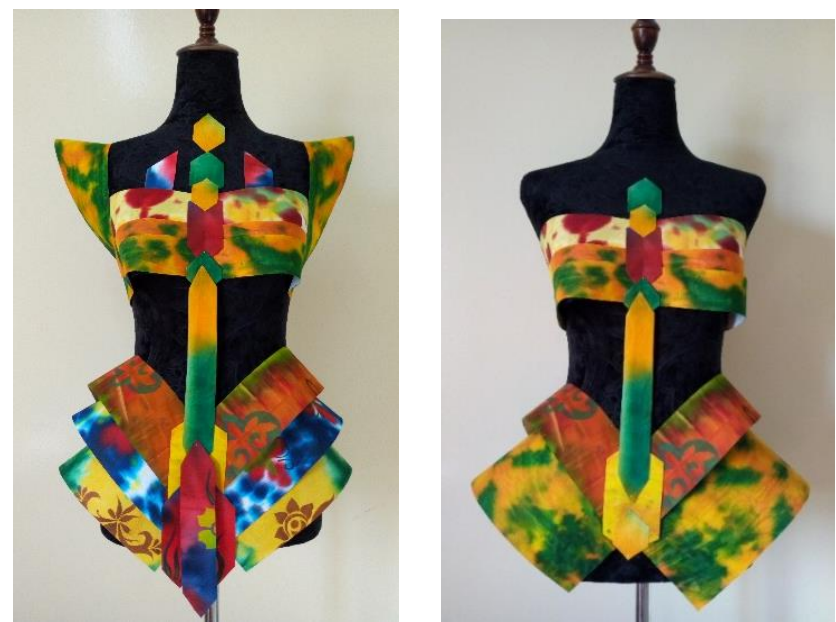

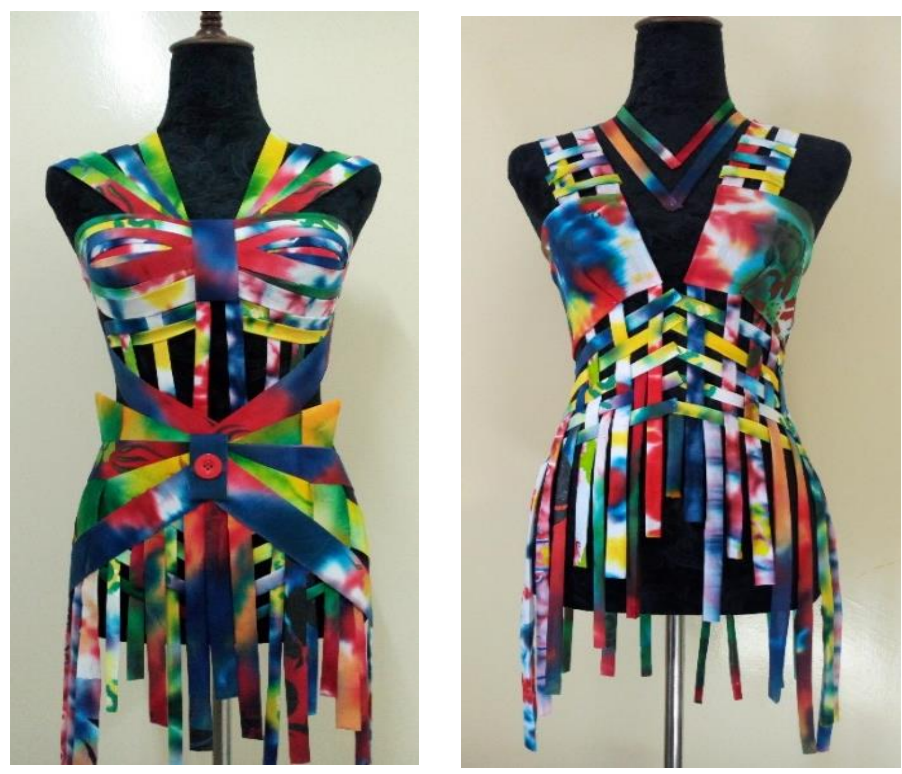

Designs 5. 6. 7. 8: Reinforced dyed ribbons, manipulated and designed on mannequin by the researcher/professor (manipulation techniques: cutting, weaving and fringing)
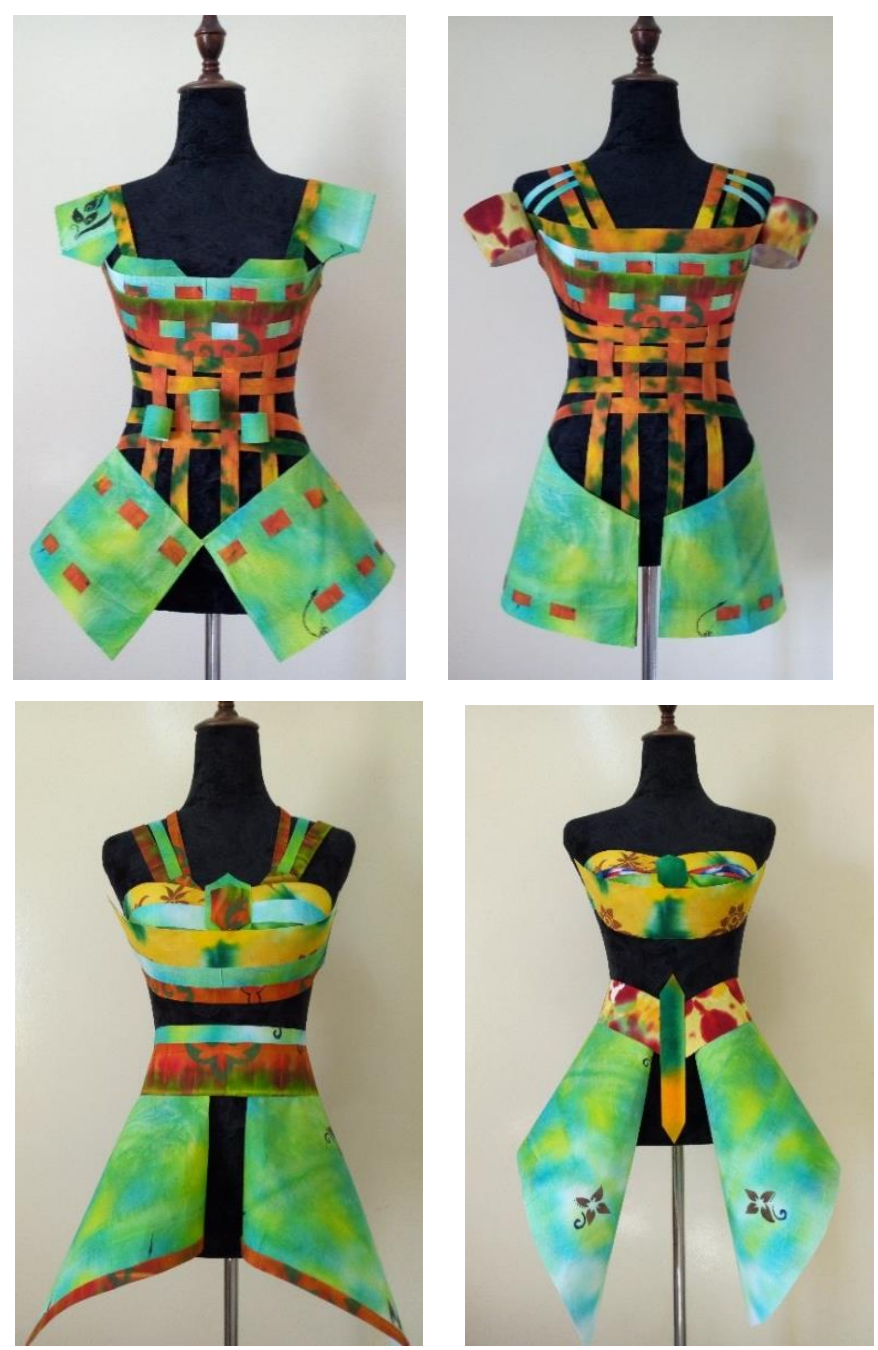

Designs 9. 10. 11. 12: Reinforced dyed ribbons, manipulated and designed on mannequin by the researcher/professor (manipulation techniques: cutting, folding, rolling and weaving) 


\section{THE STUDY RESULTS}

Data Analysis: The statistical SPS was used for data analysis. Following is a brief presentation of the results, results are related to the valuing rating scale axes.

First Axis: Investigating the creativity factors in the proposed designs- by the students, 20 collections, each collection consists of (5) proposed designs.

Table 2. Rating Scale: First axis: Investigating the creativity factors in the proposed designs

\begin{tabular}{|l|c|c|c|c|}
\hline \multicolumn{1}{|c|}{ Statement } & \multicolumn{2}{|c|}{$\begin{array}{c}\text { Control group } \\
\text { (10 collections) }\end{array}$} & \multicolumn{2}{c|}{$\begin{array}{c}\text { Experimental group } \\
\text { (10 collections) }\end{array}$} \\
\cline { 2 - 5 } & Average & Proportion & Average & Proportion \\
\hline $\begin{array}{l}\text { 1-The originality factor is achieved in the } \\
\text { collection. }\end{array}$ & 0.775 & $77.5 \%$ & 0.965 & $96.5 \%$ \\
\hline $\begin{array}{l}\text { 2-The fluency factor is achieved in the } \\
\text { collection. }\end{array}$ & 0.73 & $73 \%$ & 0.945 & $94.5 \%$ \\
\hline $\begin{array}{l}\text { 3-The flexibility factor is achieved in the } \\
\text { collection. }\end{array}$ & 0.725 & $72.5 \%$ & 0.93 & $93 \%$ \\
\hline $\begin{array}{l}\text { 4-The elaboration factor is achieved in the } \\
\text { collection. }\end{array}$ & 0.815 & $81.5 \%$ & 0.955 & $95.5 \%$ \\
\hline $\begin{array}{l}\text { 5-The problem sensitivity factor is achieved in } \\
\text { the collection. }\end{array}$ & 0.77 & $77 \%$ & 0.945 & $94.5 \%$ \\
\hline \multicolumn{1}{|c|}{ Total } & 0.763 & $76.3 \%$ & 0.948 & $94.8 \%$ \\
\hline
\end{tabular}

The total percentage of creativity factors achieving becomes for the experimental group 94.8 vs the control group 76.3, the results refer to the direct training on creativity factors within the experimental proposed designs by the reseracher, the results confirmed that analysing the methods of achieveing the creativity factors in a specific fashion collection, this help students to produce thier own collections considering the creativity factors as well.

Second Axis: The collections achieve a diversity of innovative ribbons manipulation. (6) manipulating techniques:

Table 3. Rating Scale: Second axis: Achieving the ribbons manipulating techniques

\begin{tabular}{|l|c|c|c|c|}
\hline \multirow{2}{*}{ Statement } & \multicolumn{2}{c|}{ Control group } & \multicolumn{2}{c|}{ Experimental group } \\
\cline { 2 - 5 } & Average & Proportion & Average & Proportion \\
\hline $\begin{array}{l}\text { 1- The proposed collection contains ribbons } \\
\text { manipulation techniques- Cutting. }\end{array}$ & 0.215 & $21.5 \%$ & 0.975 & $97.5 \%$ \\
\hline $\begin{array}{l}\text { 2-The proposed collection contains ribbons } \\
\text { manipulation techniques- Folding. }\end{array}$ & 0.135 & $13.5 \%$ & 0.98 & $98 \%$ \\
\hline $\begin{array}{l}\text { 3-The proposed collection contains ribbons } \\
\text { manipulation techniques- Looping. }\end{array}$ & 0.55 & $5.5 \%$ & 0.965 & $96.5 \%$ \\
\hline $\begin{array}{l}\text { 4-The proposed collection contains ribbons } \\
\text { manipulation techniques- Fringing. }\end{array}$ & 0.32 & $32 \%$ & 0.93 & $93 \%$ \\
\hline
\end{tabular}


Proceedings of INTCESS 2022- 9th International Conference on Education \& Education of Social Sciences 17-18 January 2022- Online Conference

\begin{tabular}{|c|c|c|c|c|}
\hline $\begin{array}{l}\text { 5-The proposed collection contains ribbons } \\
\text { manipulation techniques- Rolling. }\end{array}$ & 0.75 & $7.5 \%$ & 0.945 & $94.5 \%$ \\
\hline $\begin{array}{l}\text { 6-The proposed collection contains ribbons } \\
\text { manipulation techniques- Weaving. }\end{array}$ & 0.45 & $4.5 \%$ & 0.975 & $97.5 \%$ \\
\hline Total & 0.141 & $14.1 \%$ & 0.962 & $96.2 \%$ \\
\hline
\end{tabular}

The results indicates that training students on manipulation techniques support thier creative thinking skills, and help in motivating students for producing manipulated creative designs. The total percentage becomes for the experimental group 96.2 vs the control group 14.1.

Third Axis: The collection achieves the design principals successfully.

Table 4. Rating Scale: Third axis: Achieving the design principles

\begin{tabular}{|l|c|c|c|c|}
\hline \multirow{2}{*}{ Statement } & \multicolumn{2}{|c|}{ Control group } & \multicolumn{2}{c|}{ Experimental group } \\
\cline { 2 - 5 } & Average & Proportion & Average & Proportion \\
\hline $\begin{array}{l}\text { 1- The collection designs achieve (unity) } \\
\text { successfully. }\end{array}$ & 0.865 & $86.5 \%$ & 0.945 & $94.5 \%$ \\
\hline $\begin{array}{l}\text { 2- The collection designs achieve (Balance) } \\
\text { successfully. }\end{array}$ & 0.87 & $87 \%$ & 0.92 & $92 \%$ \\
\hline $\begin{array}{l}\text { 3- The collection designs achieve (Rhythm) } \\
\text { successfully. }\end{array}$ & 0.765 & $76.5 \%$ & 0.935 & $93.5 \%$ \\
\hline $\begin{array}{l}\text { 4- The collection designs achieve (Proportion) } \\
\text { successfully. }\end{array}$ & 0.725 & $72.5 \%$ & 0.885 & $88.5 \%$ \\
\hline $\begin{array}{l}\text { 5- The collection designs achieve } \\
\text { (Compatibility) successfully. }\end{array}$ & 0.845 & $84.5 \%$ & 0.93 & $93 \%$ \\
\hline \multicolumn{1}{|c|}{ Total } & 0.8363 & $83.63 \%$ & 0.923 & $92.3 \%$ \\
\hline
\end{tabular}

The results indicates that the two groups, experimental and control presented good standard of designs considering the design principles in their collections, this due to their previous learning of design principles before, in Educational Requirements Courses in addition to two Fashion Design courses. This previous study did not prevent the experimental group from obtaining the highest percentage, due to direct training on achieving design principles through the manipulation techniques in innovative design processes.

Fourth Axis: The collection achieves a successful organizing of design elements.

Table 5. Rating Scale: Fourth axis: Achieving the design elements successfully.

\begin{tabular}{|l|c|c|c|c|}
\hline \multicolumn{1}{|c|}{ Statement } & \multicolumn{2}{c|}{ Control group } & \multicolumn{2}{c|}{ Experimental group } \\
\cline { 2 - 5 } & Average & Proportion & Average & Proportion \\
\hline $\begin{array}{l}\text { 1- Organizing the internal and external Lines in } \\
\text { the collection successfully. }\end{array}$ & 0.87 & $87 \%$ & 0.915 & $91.5 \%$ \\
\hline $\begin{array}{l}\text { 2- Organizing the Shapes in the collection } \\
\text { successfully. }\end{array}$ & 0.835 & $83.5 \%$ & 0.95 & $95 \%$ \\
\hline 3- Organizing the Colours in the collection & 0.755 & $75.5 \%$ & 0.975 & $97.5 \%$ \\
\hline
\end{tabular}


Proceedings of INTCESS 2022- 9th International Conference on Education \& Education of Social Sciences 17-18 January 2022- Online Conference

\begin{tabular}{|c|c|c|c|c|}
\hline successfully. & & & & \\
\hline $\begin{array}{l}\text { 4- Organizing the Vacuums in the collection } \\
\text { successfully. }\end{array}$ & 0.625 & $62.5 \%$ & 0.925 & $92.5 \%$ \\
\hline Total & 0.7713 & $77.13 \%$ & 0.9413 & $94.13 \%$ \\
\hline
\end{tabular}

The experimental group achieved higher percentage of processing the design elements successfully, this due to the advantages which have been accessed when reinforced and manipulated the ribbons when proposing ribbons fashion, vs the control group designed the flat ribbons in poorer ideas.

\section{RECOMMENDATIONS}

1-The current study recommends adopting the proposed approach of training the students on achieving creativity factors in their designs, through analyzing the creativity factors of one theme collection -ribbons fashion in current study- this analyzing motivates their creative thinking skills and support students to design and produce creative ideas.

2- Enhancing students' creative thinking skills as fashion designers through all the practical courses, printing, dying, hand and mechanical embroidery.

3-Increasing the studies that relate to creative thinking skills for art and design students and develop them.

\section{ACKNOWLEDGEMENT}

The author would like to thank University of Nizwa for providing supplies of the experiment, and the UoN Fashion Program students for their positive response during the experiment.

\section{REFERENCE LIST}

Amabile, T. M. Conti, R. Coon, H. Lazwnby, J. Herron, M. (1996). Assessing the Work Environment for Creativity. Academy of Mangaement Journal. Vol 39, no 5, PP 1154: 1184.

Cropley, A. J. (1997). Fostering Creativity in the Classroom: General Principles. In M. A. Runco. The Creativity Research Handbook. Vol 1, Hampton Press, PP 83: 114.

Demirkan, H. (2010). From Theory to Practice. In A. Williams, M. J. Ostwald H. H. Askland. Creativity, Design and Education Theories Positions and Challenges. PP 56: 59.

Demirkan, H. Afacan, Y. (2012). Assessing Creativity in Design Education: Analysis of Creativity Factors in the First-Year Design Studio. Design Studies, no 33, PP262:278.

Elton, L. (2006). Assessing Creativity in an Unhelpful Climate. Art, design, and Communication in in Higher Education. Vol 5, no 2, PP119: 130.

Hennessey, B. A. (1994). The Consensual Assessment Technique: An examination of the Relationship between Ratings of Product and Process Creativity. Creativity Research Journal, vol 7, no 2, PP176: 192.

Horn, D. Salvendy, G. (2006). Product Creativity: Conceptual Model, Measurement and Characteristics. Theoretical Issues in Ergonomics Science, vol 7, no 4, PP395: 412.

Horn, D. Salvendy, G. (2009). Measuring Consumer Perception of Product Creativity: Impact of Satisfaction and Purchas ability. Human Factors and Ergonomics in Manufacturing. Vol 19, no 3, PP223: 240.

Jarwan, F. (2005). Teaching Thinking: Definition and Applications. Amman. Dar-Alfikr. Jordan.

Kreitler, S. Casakin, H. (2010). Motivation for Creativity: The perspective of Design and Engineering Design Studies. Implications for Design. International Journal for Technology and Design Education. Vol 20, no 4, PP477:493.

Mayer, R. E. (1999). Fivty Years of CreativityResearch in Strenberg. Handbook of Creativity. Cambraidge University Press. PP 449: 460. 
Paulus, P. Nijstad, B. (2003). Group Creativity. Oxford University Press. New York.

Sternberg, R. Lubart, T. I. (1999). The Concept of Creativity: Prospects and Paradigms, In Sternberg, R. Handbook of Creativity. Cambridge University Press. PP 3:31.

Taleb, A. Hamza, H. Wefky, E. (2013). The Effect of Using Brainstorming Strategy on Developing Creative Thinking Skills for Sixth Grade Students in Science Teaching. $20134^{\text {th }}$ International Conference on eLearning "Best Practice in Management, Design and Development of e-Courses: Standards Excellence and Creativity". PP 169: 173.

Toothpicker. (2019). The art of paper: folding, pleating and manipulation. From: https://www.toothpicnations.co.uk/my-blog/?p=38622 (17 August 2021)

Williams, M. A. Ostwald, M. Askland, H. H. (2011). Assessing Creativity in Context of Architectureal Design Education. (ALTC) the Australian Learning and Teaching Council. From: https://www.researchgate.net/publication/228701713_Assessing_creativity_in_the_context_of_archite ctural_design_education. (21 October 2021)

Williams, M. J. Askland, H. Williams, A. (2017). Changing Conceptualisation of Creativity in Design. From: file://C:/Users/khali/OneDrive/Desktop/Downloads/p4-Askland.pdf (1 January 2022)

Yamacli, R. Ozen, A. Tokman, L. Y. (2006). An Experimental Study in an Architectural Design Studio: The Search for Three-Dimensional Form and Aesthetics through Clay. The International Journal of Art and Design Education. Vol 24, no 3, PP 308: 314. 